\title{
Effect of experience with emotion provoking stimuli on water consumption in the rat'
}

\author{
K. E. Moyer ${ }^{2}$ \\ CARNEGIE INSTITUTE OF TECHNOLOGY
}

\begin{abstract}
These results show that in rats, emotionality produced by $15 \mathrm{~min}$. exposure to a strange environment, with or without shock, causes a depression in water consumption measured in the home cage. However, the effect lasts for only one day. Repeated daily exposure to shock outside the home cage results in a facilitation of water consumption after five days.
\end{abstract}

\section{Problem}

Emotionality sometimes facilitates a consummatory response (Siegel \& Siegel, 1949; Amsel \& Maltzman, 1950), sometimes depresses it (Levine, 1958), and sometimes depresses it initially but facilitates it later (Moyer \& Baenninger, 1963). It has been hypothesized (Moyer \& Baenninger, 1963) that when emotionality in the drinking situation is a new experience for the $S$, it will act as a distractor and drinking will be depressed. As the novelty wears off, drinking will return to normal and eventually exceed normal. This experiment tests that hypothesis and investigates further relationships between emotionality and consummatory behavior.

\section{Method}

The Ss were 72 naive female albino rats of the Charles River strain, 90 to 100 days of age. Shock was administered by a Model 228 Applegate stimulator in a 12 in $\mathrm{x}$ 10 in $x 8$ in grill box which had a floor of $1 / 8$ in brass rods. Calibrated tubes were used to measure water consumption.

Ss were put on $23 \mathrm{hr}$. water deprivation in single cages for 14 days. Ten min. and $1 \mathrm{hr}$. consumption was measured daily after the first nine days. Ss were divided into the following seven groups on day 15: (I) Controlleft undisturbed in home cage; (II) 5 day handled group-Ss placed in a small cage for $2 \mathrm{sec}$. and returned to home cage daily for 5 days; (III) 2 day handling group-same as group II, but undisturbed on days 2, 3, \& 4; (IV) 5 day grill box group-Ss placed in grill box for $15 \mathrm{~min}$. daily for 5 days; (V) 2 day grill box group-same as group IV but undisturbed on days 2, 3, \& 4; (VI) 5 day shock group-same as group IV, except that Ss were given 2.5 ma of shock presented non-systematically but with a mean of one shock each 20 sec. each shock was of 1.2 sec. duration; (VII) 2 day shock group-same as group VI but undisturbed on days $2,3, \& 4$.

All experimental manipulations were carried out between 10:00 and 11:30 A.M. and Ss were given water immediately after manipulation.

\section{Results}

The best estimate of the normal water consumption for each group of Ss is the amount of water consumed by that group during the five pre-experimental days. Confidence limits were established for each group by the following method: The Mean Square for Error (preexperimental days 1-5) was determined for the $10 \mathrm{~min}$. and $1 \mathrm{hr}$. measures for each of the 7 groups. A Standard Error of Estimate (SE) was then computed: $\mathrm{SE}=\sqrt{2 \text { MS error } / \mathrm{n}}$ Then: $99 \%$ confidence interval $=2.58 \mathrm{SE} ; 95 \%$ confidence interval $=1.96 \mathrm{SE}$. The results are presented in Table 1, and Fig. 1 for the $10 \mathrm{~min}$. measurements. The $1 \mathrm{hr}$. measurements are similar and the table may be obtained from the author. The control group showed that there were no general environmental changes influencing water consumption during the experimental period.

\section{Diseussion}

The results appear to confirm the hypothesis. Shock, outside the home cage, when it is a novel experience for

Table 1

Mean 10-min. water consumption in $\mathrm{ml}$ for each group on each experimental day

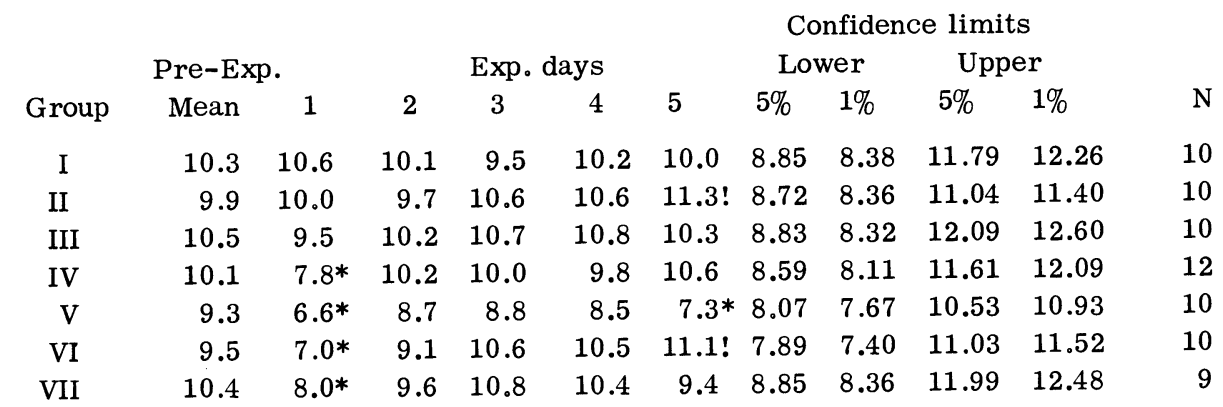

* Significant at $1 \%$ confidence level

! Significant at $5 \%$ confidence level 


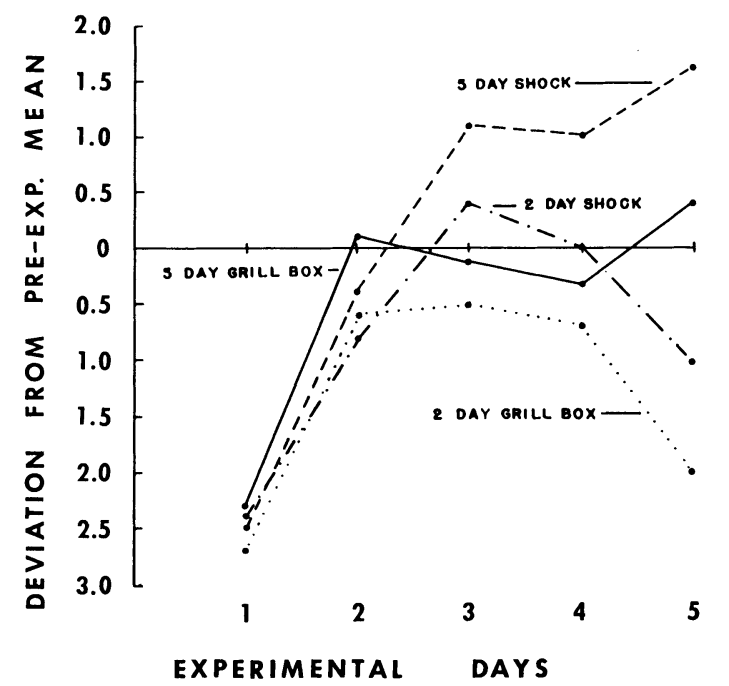

Fig. 1. Scores expressed in terms of $\mathrm{ml}$ of change from the mean score for that group on pre-experimental days. Only relevant groups are plotted.

the $\mathrm{S}$, causes a depression in water consumption in the home cage. However, the effect is short lived. As the S has repeated experience with the shock, consumption returns to normal, and ultimately becomes greater than normal. The sharp drop in water consumption is also observed if the $\mathrm{S}$ is placed in the grill box for $15 \mathrm{~min}$. before consumption is measured in the home cage even though shock is not administered. However, handling the $S$ and exposing it to a different environment for $2 \mathrm{sec}$. has no appreciable effect on consummatory behavior in the home cage.

Whether a given experimental manipulation results in depression or facilitation of the consummatory response seems to depend on the Ss past experience. In the Amsel \& Maltzman (1950) study and in the Siegel \& Siegel study (1949) in which facilitation was demonstrated, the Ss had been extensively tamed and handled prior to experimental manipulation. In the Levine study in which shock depressed consummatory behavior, the Ss had not been handled prior to experimental manipulation. In the Moyer \& Baenninger study (1963), the first experience with handling resulted in decreased consumption. After 10 days of handling, however, shock resulted in a consumption increase. In the current study, simple experience with the strange environment as well as shock, depressed drinking only on the first day. Continuted experience with shock produced an increase in consumption.
The following mechanism is proposed to integrate these findings. When the $\mathrm{S}$ is removed from the home cage and placed in a strange environment, it responds to the novelty of the situation emotionally. This emotional response includes internal visceral changes which are perceptible to the organism. Because of the hormonal nature of the internal emotional responses, they tend to persist for some time after the $\mathrm{S}$ is removed from the emotion provoking situation. On the first day the $S$ responds to these visceral sensations with attentive responses. These attentive responses (such as remaining immobile in order to avoid the interference from somatic stimulation) are sufficiently incompatible with the drinking response that drinking is depressed. (Bindra (1959), has summarized several experiments which show that novel external stimulation is accompanied by response decrement.) As the $\mathrm{S}$ has repeated experience with emotion in the home cage, the sensations are no longer novel and do not demand the S's attention with the results that there is no interference with consummatory behavior. If the pre-consumption situation continues to be highly arousing even after the novelty has worn off, as in the shocked Ss, the general increase in arousal level may result in a facilitation of the consummatory response.

It appears that the Ss habituate to the novel internal stimulation in one trial since their water consumption scores are within the normal range on the second day. However, the habituation lasts for only a few days. It will be seen in Fig. 1 that groups $5 \& 7$ which were given no pre-consumption treatment on days $2,3 \& 4$, had their water consumption depressed when again given pre-treatment on day 5 .

\section{References}

AMSEL, A., \& MALTZMAN, I. The effect upon generalized drive strength of emotionality as inferred from the level of consummatory response. J. exp. Psychol., 1950, 40, 563-569.

BINDRA, D. Stimulus change, reactions to novelty and response decrement. Psychol. Rev., 1959, 66, 96-103.

LEVINE, S. Noxious stimulation in infant and adult rate and consummatory behavior. J. comp. physiol. Psychol ., 1958, 51, 230-233.

MOYER, K. E., \& BAENNINGER, R. Effect of environment change and electric shock on water consumption in the rat. Psychol. Rep., 1963, 13, 179-185.

SIEGEL, P. S., \& SIEGEL, H. S. The effect of emotionality on the water intake of the rat.J. comp. physiol. Psychol., 1949, 42, 12-16.

1. This investigation was supported in part by a research grant M1298 from the National Institute of Health, Public Health Service. 2. The author is grateful to James Perhach and Robert Davis who rendered invaluable assistance as laboratory technicians for this experiment and to James Korn who assisted on the statistical analysis. 